\title{
Effects of calcium ions on surface characteristics and adsorptive properties of hydrous manganese dioxide
}

\author{
Ruiping Liu ${ }^{\mathrm{a}, \mathrm{b}}$, Huijuan Liu ${ }^{\mathrm{a}, *}$, Zhimin Qiang ${ }^{\mathrm{a}}$, Jiuhui $\mathrm{Qu}^{\mathrm{a}}$, Guibai Li ${ }^{\mathrm{b}}$, Dongsheng Wang ${ }^{\mathrm{a}}$ \\ a State Key Laboratory of Environmental Aquatic Chemistry, Research Center for Eco-Environmental Sciences, Chinese Academy of Sciences, Beijing 100085, China \\ b School of Municipal and Environmental Engineering, Harbin Institute of Technology, Harbin 150090, China
}

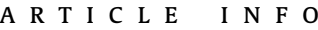

\section{Article history:}

Received 3 August 2008

Accepted 6 November 2008

Available online 9 January 2009

\section{Keywords:}

Calcium ions

Surface characteristics

Adsorption

$\delta \mathrm{MnO}_{2}$

Humic acid

Arsenic

\begin{abstract}
A B S T R A C T
The effects of calcium ions $\left(\mathrm{Ca}^{2+}\right)$ on the surface characteristics and adsorptive properties of hydrous manganese dioxide $\left(\delta \mathrm{MnO}_{2}\right)$, taking arsenic and humic acid as model pollutants, were systematically investigated. The FTIR spectra and SEM/EDX analyses indicate coordination between $\mathrm{Ca}^{2+}$ and the surface hydroxyls ( $\equiv \mathrm{Mn}-\mathrm{OH}$ ) of $\delta \mathrm{MnO}_{2}$, which leads to an increase of the surface $\zeta$ potential. $\mathrm{Ca}^{2+}$ can facilitate $\delta \mathrm{MnO}_{2}$ aggregation, as indicated by the particle size distribution (PSD) and on-line flocculating index (FI). The variation of $\delta \mathrm{MnO}_{2}$ surface characteristics that is induced by $\mathrm{Ca}^{2+}$ enhances the adsorption of humic acid (HA) and arsenic onto $\delta \mathrm{MnO}_{2}$. The adsorption of $\mathrm{HA}$ is enhanced more significantly by $\mathrm{Ca}^{2+}$ than that of arsenic, which is positively related to the coordination strength between $\mathrm{Ca}^{2+}$ and individual pollutants. The SEM/EDX analysis shows the formation of Ca-HA complexes, which have a higher affinity for $\delta \mathrm{MnO}_{2}$ than $\mathrm{HA}$. The bridging effect of $\mathrm{Ca}^{2+}$ plays a major role in enhancing $\mathrm{HA}$ adsorption onto $\delta \mathrm{MnO}_{2}$. Due to different interactions between $\mathrm{Ca}^{2+}$ and pollutants, the adsorption mechanism is pollutant-dependent in the presence of $\mathrm{Ca}^{2+}$.
\end{abstract}

(c) 2008 Elsevier Inc. All rights reserved.

\section{Introduction}

The adsorption of different pollutants (e.g., natural organic matter, phosphate, arsenic, and hydroquinone) onto natural or synthetic manganese oxides has been investigated so far with interfacial reaction mechanisms, including adsorption, surface complex formation, heterogeneous oxidation, and reductive dissolution [1-3]. However, previous studies mainly focused on prepared adsorbents. Few studies have focused on the adsorptive behaviors of adsorbents formed in situ, such as hydrous manganese dioxide $\left(\delta \mathrm{MnO}_{2}\right)$, which is produced in situ through interactions between manganese sulfate $\left(\mathrm{MnSO}_{4}\right)$ and potassium permanganate $\left(\mathrm{KMnO}_{4}\right)$.

Calcium ions $\left(\mathrm{Ca}^{2+}\right)$, a common cation in natural water environment, could impact pollutant adsorption onto adsorbents and significantly affect the reaction mechanisms involved [4,5]. For example, $\mathrm{Ca}^{2+}$ changed the dominant reactions during natural organic polyelectrolyte adsorption onto tobermorite [5] and lessened the adverse effect of silicate inhibiting arsenic co-precipitation with ferric chloride [6]. These effects were mainly ascribed by the formation of complexes between $\mathrm{Ca}^{2+}$ and metal oxides, organics, and inorganics $[2,3]$. However, previous studies mainly employed

\footnotetext{
* Corresponding author. Fax: +86 1062849160.

E-mail address: hjliu@rcees.ac.cn (H. Liu).
}

natural ores or preprepared metal oxides as adsorbents, rarely focusing on freshly formed $\delta \mathrm{MnO}_{2}$. Our earlier studies reported the positive effect of $\mathrm{Ca}^{2+}$ on humic acid (HA) and arsenic adsorption onto $\delta \mathrm{MnO}_{2}[7,8]$, but did not reveal the mechanism by which $\mathrm{Ca}^{2+}$ affects the surface characteristics and adsorptive properties of $\delta \mathrm{MnO}_{2}$.

The objectives of this study were to (1) examine the effects of $\mathrm{Ca}^{2+}$ on the surface characteristics of $\delta \mathrm{MnO}_{2}$ with FTIR, SEM/EDX, $\zeta$ potential, particle size distribution (PSD), on-line flocculating index $(\mathrm{FI})$, and BET surface area $\left(S_{\mathrm{BET}}\right)$ analyses; (2) comparatively investigate the effects of $\mathrm{Ca}^{2+}$ on $\mathrm{HA}$ and arsenic adsorption onto $\delta \mathrm{MnO}_{2}$; and (3) propose the dominant mechanisms of $\mathrm{Ca}^{2+}$ facilitating the adsorption of model pollutants onto $\delta \mathrm{MnO}_{2}$.

\section{Materials and methods}

\subsection{Reagents and $\delta \mathrm{MnO}_{2}$ preparation}

Chemical grade HA consisting of $62.53 \%$ C, $32.34 \%$ O, and $4.80 \%$ $\mathrm{H}$ was obtained from Tianjin Chemical Reagents Company. To prepare a stock solution, $\mathrm{HA}$ ash was first dissolved in $2 \mathrm{M} \mathrm{NaOH}$, sonicated for $30 \mathrm{~min}$, and then kept in darkness airtight at $4{ }^{\circ} \mathrm{C}$ for 3 months for the dissolution of as much $\mathrm{HA}$ as possible. It was diluted and filtered through $0.45-\mu \mathrm{m}$ cellulose acetate filters twice before use. The sodium arsenite $\left(\mathrm{NaAsO}_{2}\right)$ and sodium arse- 
nate $\left(\mathrm{NaAsO}_{3}\right)$ stock solutions were prepared in de-ionized water every 10 days.

$\delta \mathrm{MnO}_{2}$ was prepared through a reaction between $\mathrm{MnSO}_{4}$ and $\mathrm{KMnO}_{4}$ following the procedures reported in our previous publication [7]. X-ray diffraction analysis (Shimadzu Co., Japan) showed a low degree of crystallinity, indicating its similarity to what others referred to as $\delta \mathrm{MnO}_{2}$.

\subsection{Experimental methods}

Sodium nitrate $\left(\mathrm{NaNO}_{3}\right)$ was used to adjust the background ionic strength when necessary. Calcium nitrate $\left(\mathrm{Ca}\left(\mathrm{NO}_{3}\right)_{2}\right)$ and model pollutants (e.g., HA and arsenic) were added into the reaction solution at desired concentrations and $\mathrm{pH}$ was adjusted thereafter. Batch experiments on adsorption were conducted in capped flasks with continuous rotary shaking $(125 \mathrm{rpm})$ at $25 \pm 1^{\circ} \mathrm{C}$ for $60 \mathrm{~min}$. Samples were filtered through $0.45-\mu \mathrm{m}$ membrane filters to analyze total organic carbon (TOC) and arsenic concentrations in the filtrate. The adsorption density of these two pollutants on $\delta \mathrm{MnO}_{2}$ was calculated by the formula

adsorption density

$$
=\left([\text { pollutant }]_{\text {initial }}-[\text { pollutant }]_{\text {final }}\right) / \delta \mathrm{MnO}_{2} \text { dosage, }
$$

where [pollutant] $]_{\text {initial }}$ means the initial concentration of a pollutant, and [pollutant] final stands for the final concentration of a pollutant.

To examine the effect of $\mathrm{Ca}^{2+}$ on $\delta \mathrm{MnO}_{2}$ aggregation, batch experiments were conducted in glass beakers with rapid mixing (150 rpm, $1 \mathrm{~min}$ ) and subsequent slow mixing (50 rpm, $20 \mathrm{~min}$ ). Samples were continuously withdrawn $10 \mathrm{~mm}$ below the water level with a peristaltic pump for on-line FI analysis.

While the interactions between $\mathrm{Ca}^{2+}$ and HA were investigated, $2 \mathrm{mM} \mathrm{Ca}^{2+}$ was added into the HA solution $(17.1 \mathrm{mg} / \mathrm{L}$ DOC, dissolved organic carbon) and the reaction was allowed to proceed for $60 \mathrm{~min}$. The solution was thereafter filtered through a $0.45-$ $\mu \mathrm{m}$ membrane filter, and the membrane residue was washed with de-ionized water and freeze-dried for SEM/EDX analysis.

\subsection{Analytical methods}

The elemental composition of HA was determined with a VarioEL elemental analyzer (Elementar Co.) without pretreatment. FTIR spectra were recorded in $\mathrm{KBr}$ pellets using an FT-NIR Raman spectrometer (Perkin-Elmer Co.). Surface elemental ratio was analyzed by an S-3000N scanning electron microscope (SEM, Hitachi Co.) coupled with an energy-dispersive X-ray analyzer (EDX, EDAX Inc.). Samples were washed with de-ionized water, centrifuged, and freeze-dried before analysis.

$S_{\mathrm{BET}}$ was determined by the single-point Brunauer-EmmettTeller (BET) $\mathrm{N}_{2}$ adsorption method using an ASAP 2000 accelerated surface area and porosimetry analyzer (Micromeritics Co.). Suspensions were first centrifuged and freeze-dried under vacuum and then resuspended in acetone and freeze-dried again [7] for $S_{\mathrm{BET}}$ analysis.

The electrokinetic potential ( $\zeta$ potential) of $\delta \mathrm{MnO}_{2}$ was measured with a zeta potential analyzer, Model Zetasizer2000 (Malvern Co.), in triplicate. The average volumetric particle diameter (AVPD) and PSD were determined with a Mastersizer2000 laser particle size analyzer (Malvern Co.).

A PDA2000 photometric dispersion analyzer (Rank Bros Ltd.) was employed to monitor the on-line FI. The PDA monitors the turbidity fluctuation of particles in a flow-through cell, providing useful information on particle diameter variation and on-line aggregation [9].

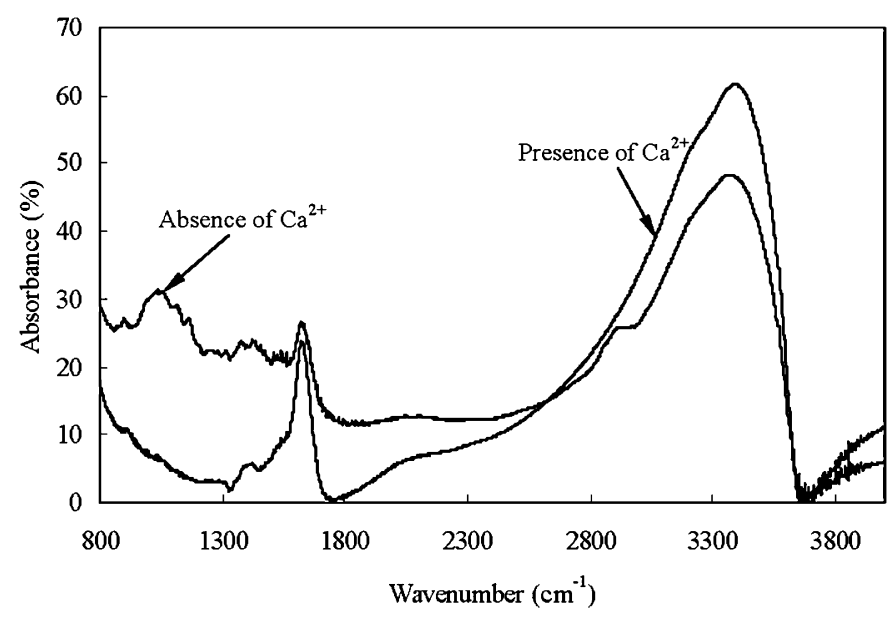

Fig. 1. FTIR spectra of $\delta \mathrm{MnO}_{2}$ in the presence or absence of $\mathrm{Ca}^{2+}$.

TOC was determined by UV-persulfate oxidation with a Phoenix 8000 TOC analyzer (Tekmar-Dohrmann Co.). Arsenic concentrations were determined by the hydride generation-atomic fluorescence spectroscopy (HG-AFS) method with an AF-610A atomic fluorescence spectrometer (Rayleigh Analytical Instrument Co., China). The arsenic detection limit of the instrument was $2 \mu \mathrm{g} / \mathrm{L}$.

\section{Results and discussion}

\subsection{Effects of $\mathrm{Ca}^{2+}$ on the surface characteristics of $\delta \mathrm{MnO}_{2}$}

3.1.1. Effect of $\mathrm{Ca}^{2+}$ on the surface functional groups of $\delta \mathrm{MnO}_{2}$

The FTIR spectra of $\delta \mathrm{MnO}_{2}$ (Fig. 1) showed quite similar trends between 1600 and $4000 \mathrm{~cm}^{-1}$ in the presence or absence of $\mathrm{Ca}^{2+}$, and both spectra indicated the presence of physisorbed water molecules. The shoulder bands at $3380 \mathrm{~cm}^{-1}$ corresponded to the structural $-\mathrm{OH}$ stretching vibration $\left(v_{\mathrm{OH}}\right)$. The bands at $1624 \mathrm{~cm}^{-1}$ were related to the $\mathrm{H}-\mathrm{O}-\mathrm{H}$ bending $\left(\delta_{\mathrm{OH}}\right)$, indicating the deformation of adsorbed water molecules.

In the absence of $\mathrm{Ca}^{2+}$, the shoulder band at $1034 \mathrm{~cm}^{-1}$ was assigned to the vibration of surface hydroxyl groups (e.g., $\equiv \mathrm{Mn}-$ $\mathrm{OH})$ within metal oxides [10]. In the presence of $\mathrm{Ca}^{2+}$, this band disappeared, due to the formation of complexes between $\mathrm{Ca}^{2+}$ and $\equiv \mathrm{Mn}-\mathrm{OH}$. The $\mathrm{pH}_{\mathrm{PZC}}$ (point of zero charge) of $\delta \mathrm{MnO}_{2}$ was reported to be about $\mathrm{pH} 3.0$ [7]. In different $\mathrm{pH}$ ranges, $\delta \mathrm{MnO}_{2}$ exhibits different surface charges through surface dissolution and hydrolysis reactions as follows:

$$
\begin{aligned}
& \equiv \mathrm{Mn}-\mathrm{OH}+\mathrm{H}_{2} \mathrm{O} \rightarrow \equiv \mathrm{Mn}_{-} \mathrm{OH}_{2}^{+}+\mathrm{OH}^{-} \quad\left(\mathrm{pH}<\mathrm{pH}_{\mathrm{PZC}}\right), \\
& \equiv \mathrm{Mn}-\mathrm{OH} \rightarrow \equiv \mathrm{Mn}^{-} \mathrm{O}^{-}+\mathrm{H}^{+} \quad(\mathrm{pH}>\mathrm{pH} \mathrm{PZC}) .
\end{aligned}
$$

$\mathrm{Ca}^{2+}$ is able to form complexes with $\equiv \mathrm{Mn}-\mathrm{OH}$ and contributes to the disappearance of $\equiv \mathrm{Mn}-\mathrm{OH}$ through the following reactions:

$\equiv \mathrm{Mn}-\mathrm{OH}+\mathrm{Ca}^{2+} \rightarrow \equiv \mathrm{Mn}-\mathrm{O}-\mathrm{Ca}^{+}+\mathrm{H}^{+}$

$2[\equiv \mathrm{Mn}-\mathrm{OH}]+\mathrm{Ca}^{2+} \rightarrow \equiv \mathrm{Mn}-\mathrm{O}-\mathrm{Ca}-\mathrm{O}-\mathrm{Mn} \equiv+2 \mathrm{H}^{+}$.

Our SEM/EDX analysis indicated the presence of elemental Ca on the $\delta \mathrm{MnO}_{2}$ surface, confirming the occurrence of reactions between $\mathrm{Ca}^{2+}$ and $\equiv \mathrm{Mn}-\mathrm{OH}$.

\subsubsection{Effect of $\mathrm{Ca}^{2+}$ concentration on the surface charge of $\delta \mathrm{MnO}_{2}$}

The effect of $\mathrm{Ca}^{2+}$ concentration on the $\zeta$ potential of $\delta \mathrm{MnO}_{2}$ is shown in Fig. 2. Results indicate that at $\mathrm{pH} 7.0, \delta \mathrm{MnO}_{2}$ had a low $\zeta$ potential of $-23.4 \mathrm{mV}$, which increased to $-12.4 \mathrm{mV}$ at $0.2 \mathrm{mM} \mathrm{Ca}^{2+}$ and $-1.5 \mathrm{mV}$ at $0.6 \mathrm{mM} \mathrm{Ca}^{2+}$. Further increasing the $\mathrm{Ca}^{2+}$ concentration did not notably increase the $\zeta$ potential. In the presence of $\mathrm{HA}(4.76 \mathrm{mg} / \mathrm{L}$ as $\mathrm{DOC})$, the addition of $\mathrm{Ca}^{2+}$, 


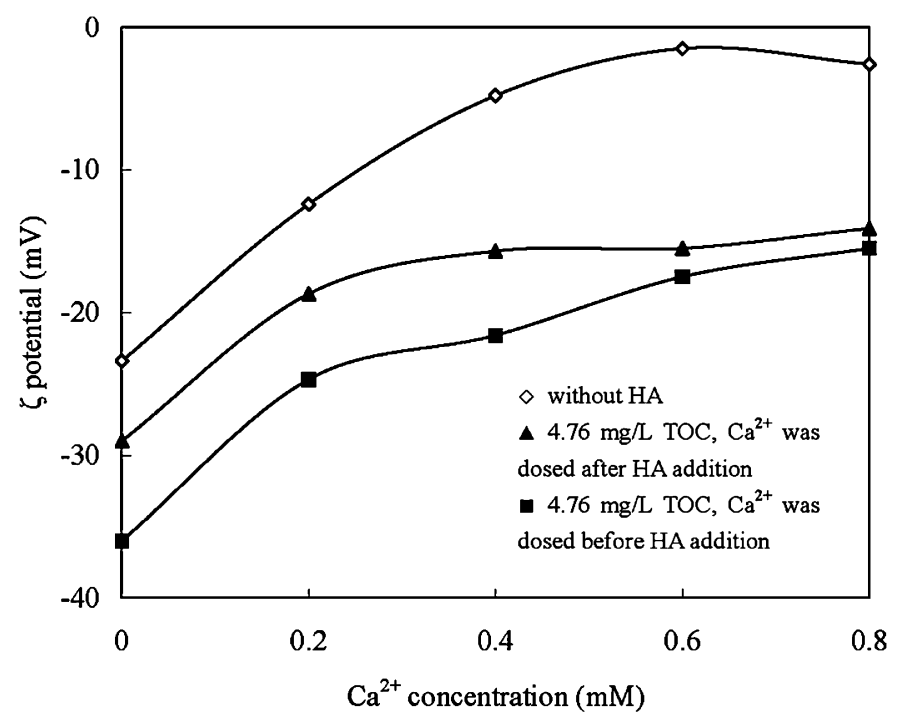

Fig. 2. Effect of $\mathrm{Ca}^{2+}$ concentration on the $\zeta$ potential of $\delta \mathrm{MnO}_{2}$ (pH 7.0). Experimental conditions: open symbols-in the absence of HA; solid symbols-in the presence of $4.76 \mathrm{mg} / \mathrm{L} \mathrm{HA}$ as TOC.

either before or after HA addition also led to a $\zeta$ potential increase. For example, $\mathrm{Ca}^{2+}$ increased the $\zeta$ potential of $\delta \mathrm{MnO}_{2}$ from $-29.0 \mathrm{mV}\left(\right.$ no $\left.\mathrm{Ca}^{2+}\right)$ to $-14.1 \mathrm{mV}\left(0.8 \mathrm{mM} \mathrm{Ca}^{2+}\right)$ when $\mathrm{HA}$ was predissolved in the reaction solution. $\delta \mathrm{MnO}_{2}$, with $\mathrm{pH}_{\mathrm{PZC}}$ about 3.0, was a highly acidic oxide and showed a high adsorbing potential for $\mathrm{Ca}^{2+} . \mathrm{Ca}^{2+}$ could compress the diffuse double electrical layer of $\delta \mathrm{MnO}_{2}$. Additionally, the interactions between $\mathrm{Ca}^{2+}$ and $\equiv \mathrm{Mn}-$ $\mathrm{OH}$ could increase the surface potential through ion exchange and surface complexation reactions [11].

Comparatively, greater $\zeta$-potential increase was observed when $\mathrm{Ca}^{2+}$ was added after HA, especially at lower $\mathrm{Ca}^{2+}$ concentrations. The presence of HA decreased the amount of $\mathrm{Ca}^{2+}$ available for the diffuse double electrical layer compression, owing to competitive complexation between $\mathrm{Ca}^{2+}$ and the acidic functional groups within HA. When HA was added after $\mathrm{Ca}^{2+}$, the positive charge of $\equiv \mathrm{Mn}-\mathrm{O}-\mathrm{Ca}^{+}$species was largely decreased due to the electrical interaction between $\equiv \mathrm{Mn}-\mathrm{O}-\mathrm{Ca}^{+}$and HA. However, if HA was added before $\mathrm{Ca}^{2+}$, the $\equiv \mathrm{Mn}-\mathrm{OH}$ first interacted with the hydrogen bonds within HA through the hydrogen-bonding effect. This effect decreased the required $\mathrm{Ca}^{2+}$ amount for surface $\equiv \mathrm{Mn}-\mathrm{OH}$ complexation, providing more $\mathrm{Ca}^{2+}$ to compress the diffuse double electric layer.

\subsubsection{Effect of $\mathrm{Ca}^{2+}$ concentration on the stability and aggregation of $\delta \mathrm{MnO}_{2}$}

The effect of $\mathrm{Ca}^{2+}$ concentration on the stability and aggregation of $\delta \mathrm{MnO}_{2}$ is shown in Fig. 3. Results in Fig. 3a indicate that more than $99 \%$ of $\delta \mathrm{MnO}_{2}$ particles were below $0.5 \mu \mathrm{m}$ in the absence of $\mathrm{Ca}^{2+}$. However, about $95 \%$ of $\delta \mathrm{MnO}_{2}$ particles were larger than $3.6 \mu \mathrm{m}$ after $1.0 \mathrm{mM} \mathrm{Ca}^{2+}$ was added. It is clearly seen that $\mathrm{Ca}^{2+}$ significantly promoted the aggregation of $\delta \mathrm{MnO}_{2}$ particles.

$\mathrm{Ca}^{2+}$ could significantly increase the AVPD of $\delta \mathrm{MnO}_{2}$. In the absence of $\mathrm{Ca}^{2+}$, the AVPD value of $\delta \mathrm{MnO}_{2}$ was approximately $0.1 \mu \mathrm{m}$. When the $\mathrm{Ca}^{2+}$ concentration was increased to 0.2 and $0.4 \mathrm{mM}$, the AVPD value remarkably increased to 15.0 and $24.2 \mu \mathrm{m}$, respectively. Further increasing the $\mathrm{Ca}^{2+}$ concentrations to 0.6 and $0.8 \mathrm{mM}$ did not increase the AVPD notably. Since $0.6 \mathrm{mM} \mathrm{Ca}^{2+}$ was enough to increase the $\zeta$ potential (Fig. 2), it is inferred that $\mathrm{Ca}^{2+}$ promoted the aggregation of $\delta \mathrm{MnO}_{2}$ particles through decreasing the electrostatic repulsive forces.

The $S_{\mathrm{BET}}$ analysis of $\delta \mathrm{MnO}_{2}$ was in good accordance with the PSD analysis. The $S_{\mathrm{BET}}$ of $\delta \mathrm{MnO}_{2}$ was determined to be 117.4

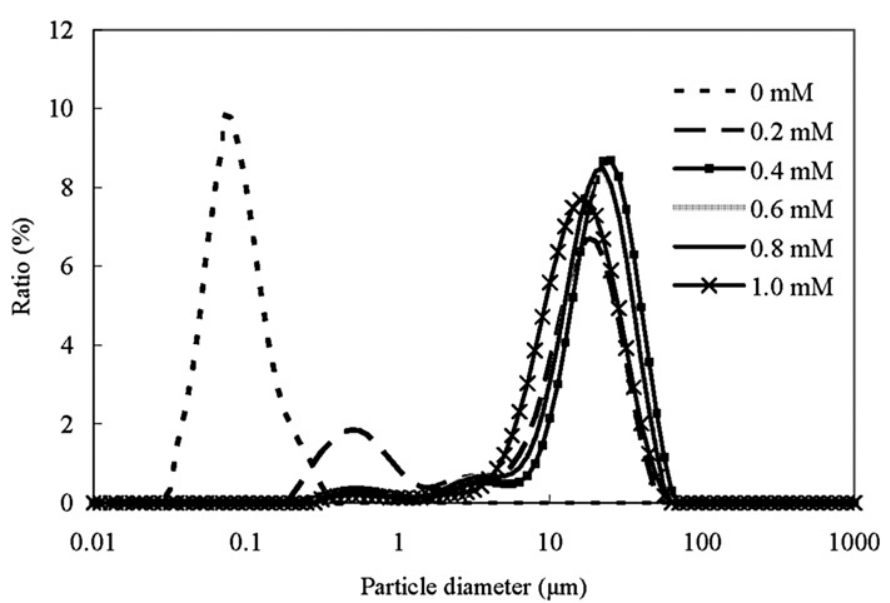

(a)

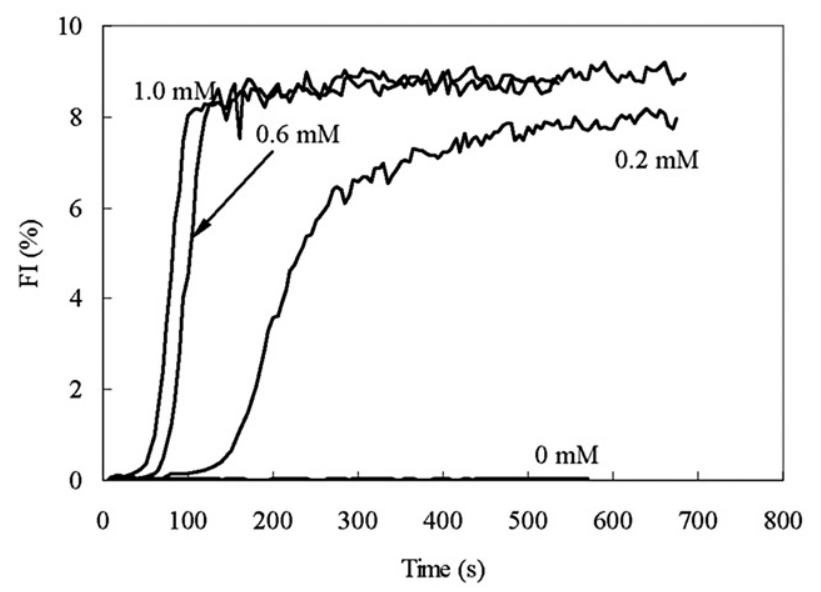

(b)

Fig. 3. Effect of $\mathrm{Ca}^{2+}$ concentration on (a) the particle size distribution and (b) the FI of $\delta \mathrm{MnO}_{2}$.

$\mathrm{m}^{2} / \mathrm{g}$, which was much higher than that of commercial $\beta \mathrm{MnO}_{2}$ $\left(29.3 \mathrm{~m}^{2} / \mathrm{g}\right)$. The high $S_{\mathrm{BET}}$ value was ascribed to the amorphous status of $\delta \mathrm{MnO}_{2}$, whose XRD pattern revealed no obvious crystalline peaks. The addition of $1 \mathrm{mM} \mathrm{Ca}^{2+}$ decreased the $S_{\mathrm{BET}}$ to $80.5 \mathrm{~m}^{2} / \mathrm{g}$ due to the aggregation of $\delta \mathrm{MnO}_{2}$ particles.

It is noted that the $\delta \mathrm{MnO}_{2}$ aggregation was significantly enhanced even at a $\mathrm{Ca}^{2+}$ concentration as low as $0.2 \mathrm{mM}$. Thus, it can be inferred that the $\mathrm{Ca}^{2+}$ concentration in most natural water environments [12] is enough to promote $\delta \mathrm{MnO}_{2}$ aggregation.

$\mathrm{Ca}^{2+}$ also impacted the dynamic $\delta \mathrm{MnO}_{2}$ aggregation at different $\mathrm{Ca}^{2+}$ concentrations (Fig. 3b). Results indicate that the FI value of $\delta \mathrm{MnO}_{2}$ continuously increased with increasing $\mathrm{Ca}^{2+}$ concentration. In contrast, the FI value stayed consistently zero in the absence of $\mathrm{Ca}^{2+}$, indicating the tiny and dispersed $\delta \mathrm{MnO}_{2}$ particles. A low $\mathrm{Ca}^{2+}$ concentration of $0.2 \mathrm{mM}$ could increase the FI to a maximal value of $7.5 \%$. At $0.6 \mathrm{mM} \mathrm{Ca}^{2+}$, the maximal $\mathrm{FI}$ value was further increased to $9.2 \%$, with a correspondingly shortened critical time. No distinct difference was observed between 0.6 and $1.0 \mathrm{mM} \mathrm{Ca}{ }^{2+}$, which was in agreement with PSD data.

This result is of practical interest. Aqueous $\mathrm{Mn}(\mathrm{II})$ should be minimized in drinking water treatment due to its unfavorable effect on taste, color, and turbidity. $\mathrm{Mn}(\mathrm{II})$ is generally oxidized to $\delta \mathrm{MnO}_{2}$, which can be readily removed through subsequent filtration. Our result shows that $\mathrm{Ca}^{2+}$, which is commonly present in drinking water resources, can notably enhance $\delta \mathrm{MnO}_{2}$ removal by promoting $\delta \mathrm{MnO}_{2}$ aggregation. 

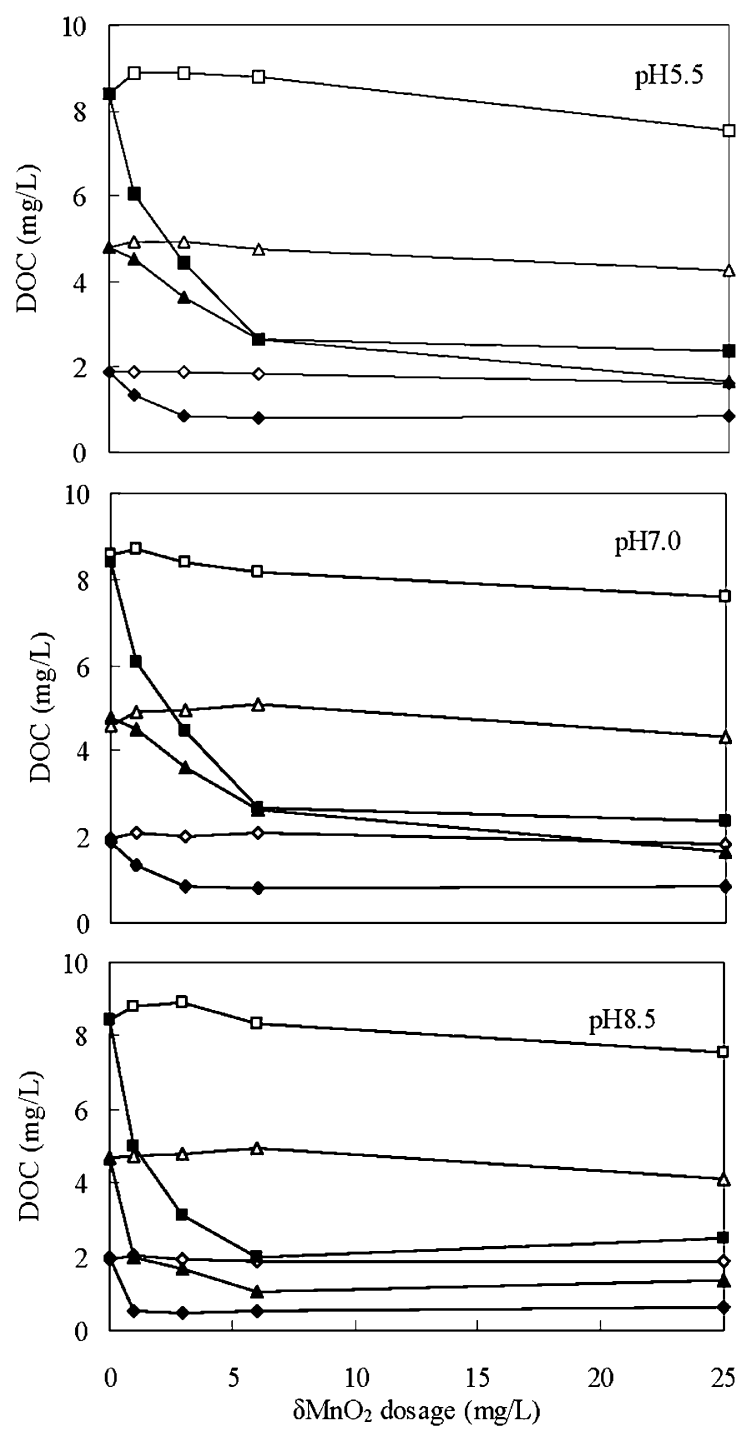

Fig. 4. Effect of $\mathrm{Ca}^{2+}$ on $\mathrm{HA}$ adsorption onto $\delta \mathrm{MnO}_{2}$ at different $\mathrm{pH}$ values: open symbols-in the absence of $1 \mathrm{mM} \mathrm{Ca}^{2+}$; solid symbols-in the presence of $\mathrm{Ca}^{2+}$.

\subsection{Effects of $\mathrm{Ca}^{2+}$ on $\mathrm{HA}$ and arsenic adsorption onto $\delta \mathrm{MnO}_{2}$ and their mechanisms}

\subsubsection{Effect of $\mathrm{Ca}^{2+}$ on $\mathrm{HA}$ adsorption onto $\delta \mathrm{MnO}_{2}$}

The effect of $\mathrm{Ca}^{2+}$ on $\mathrm{HA}$ adsorption onto $\delta \mathrm{MnO}_{2}$ at different $\mathrm{pH}$ values is shown in Fig. 4. Results indicate that little HA was adsorbed by $\delta \mathrm{MnO}_{2}$ in the absence of $\mathrm{Ca}^{2+}$. However, $1.0 \mathrm{mM} \mathrm{Ca}{ }^{2+}$ significantly increased HA adsorption, with a maximal removal efficiency of $77.0 \%$ at $\mathrm{pH}$ 7.0. The corresponding adsorption density was calculated to be $0.97 \mathrm{mg}-\mathrm{TOC} / \mathrm{mg}-\delta \mathrm{MnO}_{2}$ under this condition. Similar trends were observed at $\mathrm{pH} 5.5$ and 8.5, and more HA could be removed as the $\mathrm{pH}$ increased.

The mechanisms of humic substance adsorption onto metal oxides generally include anion exchange (electrostatic interaction), ligand exchange (surface complexation), hydrophobic interaction, entropic effects, hydrogen bonding, and cation bridging [13]. In the absence of $\mathrm{Ca}^{2+}, \delta \mathrm{MnO}_{2}$ adsorbs $\mathrm{HA}$ mainly through the reactions:

$\mathrm{pH}<\mathrm{pH}_{\mathrm{PzC}}: \quad \equiv \mathrm{Mn}-\mathrm{OH}_{2}^{+}+\mathrm{L}^{-}=\equiv \mathrm{Mn}-\mathrm{OH}_{2} \mathrm{~L}$

(electrostatic interaction),

$\mathrm{pH}>\mathrm{pH}_{\mathrm{PZC}}: \equiv \mathrm{MnOHOH}^{-}+\mathrm{HL}^{\prime}=\equiv(\mathrm{MnOH}) \mathrm{OH}^{-} \ldots \mathrm{HL}^{\prime}$

(hydrogen bonding),

$\equiv \mathrm{MnOHOH}^{-}+\mathrm{L}^{-}=\equiv \mathrm{MnOHL}^{-}+\mathrm{OH}^{-}$

(ligand exchange),
Table 1

Effect of $\mathrm{Ca}^{2+}$ concentration on arsenic removal by $\delta \mathrm{MnO}_{2}\left(0.63 \mathrm{mg} / \mathrm{L}[\mathrm{As}(\mathrm{III})]_{0}\right.$, $6 \mathrm{mg} / \mathrm{L} \delta \mathrm{MnO}_{2}$ ).

\begin{tabular}{llcc}
\hline $\begin{array}{l}\mathrm{Ca}^{2+} \\
(\mathrm{mM})\end{array}$ & $\begin{array}{l}\mathrm{HA} \text { as DOC } \\
(\mathrm{mg} / \mathrm{L})\end{array}$ & $\begin{array}{l}\text { As removal } \\
(\%)\end{array}$ & $\begin{array}{l}\text { As adsorption density } \\
\left(\mathrm{mg}-\mathrm{As} / \mathrm{g}-\delta \mathrm{MnO}_{2}\right)\end{array}$ \\
\hline 0 & 0 & 2.1 & 2.1 \\
1.0 & 0 & 18.3 & 19.3 \\
0 & 4.62 & 2.0 & 4.3 \\
0.4 & 4.62 & 14.0 & 14.8 \\
1.0 & 4.62 & 16.9 & 17.9 \\
0 & 8.62 & 0.8 & 4.0 \\
0.1 & 8.62 & 7.4 & 7.8 \\
1.0 & 8.62 & 21.1 & 17.9 \\
\hline
\end{tabular}

where $\mathrm{L}^{-}$and $\mathrm{HL}^{\prime}$ respectively represent the acidic and neutral forms of $\mathrm{HA}$ ligands, and $\equiv \mathrm{MnOHOH}^{-}$stands for the hydrolyzed $\equiv \mathrm{Mn}^{-} \mathrm{O}^{-}$.

However, HA was negatively charged around neutral $\mathrm{pH}$ due to the deprotonation of its surface acidic groups, such as carboxylic $(-\mathrm{COOH})$ and phenolic $(-\mathrm{ArOH})$ groups. $\delta \mathrm{MnO}_{2}$ was also negatively charged, with a $\zeta$ potential of $-23.4 \mathrm{mV}$ at $\mathrm{pH} 7.0$ (Fig. 2). The repulsive force between $\mathrm{HA}$ and $\delta \mathrm{MnO}_{2}$ inhibited the electrostatic and hydrogen bonding reactions, thus leading to limited HA removal.

$\mathrm{Ca}^{2+}$ acted as a cation bridge between $\mathrm{HA}$ and $\delta \mathrm{MnO}_{2}$ to facilitate $\mathrm{HA}$ adsorption. First, $\mathrm{Ca}^{2+}$ could increase the $\zeta$ potential of $\delta \mathrm{MnO}_{2}$, thus decreasing the repulsive force between $\delta \mathrm{MnO}_{2}$ and HA. Yao and Millero reported that $\mathrm{Ca}^{2+}$ could enhance phosphate adsorption onto $\delta \mathrm{MnO}_{2}$ by reversing the surface charge of $\delta \mathrm{MnO}_{2}$ from negative to positive [14]. In addition, $\mathrm{Ca}^{2+}$ could coordinate with the $-\mathrm{COO}^{-}$and $-\mathrm{ArO}^{-}$groups to form more easily adsorbed metal/humic complexes. Our SEM/EDX analysis showed an elemental ratio $(\mathrm{C} / \mathrm{Ca})$ of $38: 1$, which demonstrated the occurrence of the complexation between $\mathrm{Ca}^{2+}$ and HA. Kaneco et al. reported that $\mathrm{Cu}^{2+}$ and $\mathrm{Al}^{3+}$ enhanced fuvic acid adsorption onto metal oxides [3]. Schulthess and Huang reported that metal/humic complexes exhibited a higher adsorption density on metal oxides than humic substances alone [15].

\subsubsection{Effect of $\mathrm{Ca}^{2+}$ on arsenic adsorption onto $\delta \mathrm{MnO}_{2}$}

$\mathrm{Ca}^{2+}$ also exerted a positive effect on arsenic adsorption onto $\delta \mathrm{MnO}_{2}$, as shown in Table 1 . Quantitatively, $1.0 \mathrm{mM} \mathrm{Ca}{ }^{2+}$ could increase the adsorption density of As from 2.1 to $19.3 \mathrm{mg} \mathrm{As} / \mathrm{g}$ $\delta \mathrm{MnO}_{2}$. In the presence of HA $(4.62 \mathrm{mg} / \mathrm{L} \mathrm{DOC})$, the removal efficiency of As was increased from 2.0\% (no $\left.\mathrm{Ca}^{2+}\right)$ to $14.0 \%(0.4 \mathrm{mM}$ $\mathrm{Ca}^{2+}$ ) and $16.9 \%\left(1.0 \mathrm{mM} \mathrm{Ca}{ }^{2+}\right)$. Our former study also indicated the limited potential of $\mathrm{Ca}^{2+}$ to facilitate the adsorption of arsenic onto $\delta \mathrm{MnO}_{2}$ [16]. Generally, in comparison with HA removal, the enhancement of arsenic removal by $\mathrm{Ca}^{2+}$ was not so significant.

In the neutral $\mathrm{pH}$ range, $\mathrm{As}(\mathrm{V})$ exists in the forms of $\mathrm{H}_{2} \mathrm{AsO}_{4}^{-}$ and $\mathrm{HAsO}_{4}^{2-}$, whereas $\mathrm{H}_{3} \mathrm{AsO}_{3}$ is the predominant $\mathrm{As}(\mathrm{III})$ species and less than $10 \%$ of $\mathrm{As}(\mathrm{III})$ is in the form of $\mathrm{H}_{2} \mathrm{AsO}_{3}^{-}$. As(V) was adsorbed onto manganese oxides through complexation between $\mathrm{As}(\mathrm{V})$ and surface $\mathrm{Mn}-\mathrm{OH}[1]$. However, $\mathrm{As}(\mathrm{III})$ adsorption involved additional oxidation of $\mathrm{As}(\mathrm{III})$ to $\mathrm{As}(\mathrm{V})$ [1].

As mentioned above, $\mathrm{Ca}^{2+}$ could enhance $\delta \mathrm{MnO}_{2}$ aggregation, thus decreasing the amount of $\delta \mathrm{MnO}_{2}$ passing through the filtration process. As a result, more arsenic was removed through adsorption by $\delta \mathrm{MnO}_{2}$ and subsequent filtration.

However, $\mathrm{Ca}^{2+}$ and arsenic species could only form weak complexes. Swash and Monhemius reported that $\mathrm{CaHAsO}_{4}, \mathrm{CaHAsO}_{4}$. $\mathrm{H}_{2} \mathrm{O}$, and $\mathrm{CaHAsO}_{4} \cdot 2 \mathrm{H}_{2} \mathrm{O}$ were the main species formed from the interactions between arsenate and $\mathrm{Ca}^{2+}$, with their water solubility varying from $2.9 \times 10^{-2}$ to $5.8 \times 10^{-2} \mathrm{M}$ [17]. Qiu and Liu reported that the water solubility of $\mathrm{Ca}\left(\mathrm{AsO}_{2}\right)_{2}$ was $3.5 \times 10^{-3} \mathrm{M}$ [18]. In this study, the concentration product of $\mathrm{Ca}^{2+}$ and arsenic 


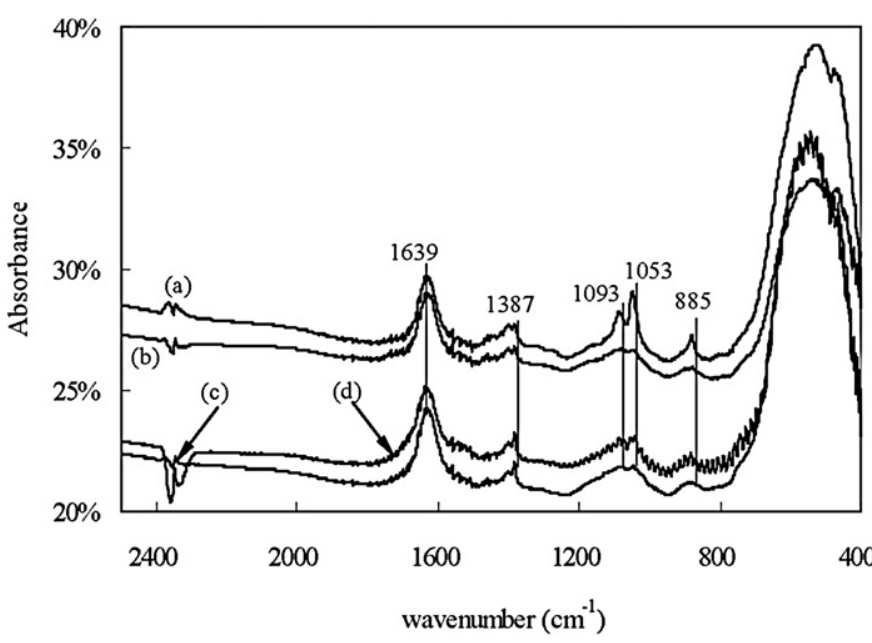

Fig. 5. FTIR analysis of $\delta \mathrm{MnO}_{2}$ with adsorbed arsenic species: (a) initial $\mathrm{As}(\mathrm{V}), 0 \mathrm{mM}$ $\mathrm{Ca}^{2+}$; (b) initial $\mathrm{As}(\mathrm{V}), 1 \mathrm{mM} \mathrm{Ca}{ }^{2+}$; (c) initial $\mathrm{As}(\mathrm{III}), 0 \mathrm{mM} \mathrm{Ca}{ }^{2+}$; and (d) initial As(III), $1 \mathrm{mM} \mathrm{Ca}{ }^{2+}$. Experimental conditions: initial arsenic concentration was $10 \mathrm{mg} / \mathrm{L}, 100 \mathrm{mg} / \mathrm{L} \delta \mathrm{MnO}_{2}, 50 \mathrm{mM} \mathrm{NaNO}$.

species was much lower than the water solubility of corresponding species, implying weak complexation between $\mathrm{Ca}^{2+}$ and arsenic species.

FTIR analysis was employed to investigate the bridging effect of $\mathrm{Ca}^{2+}$ on the adsorption of arsenic species by $\delta \mathrm{MnO}_{2}$ (Fig. 5). Samples a and $\mathrm{b}$ denoted the $\delta \mathrm{MnO}_{2}$ with adsorbed As species in the presence of initial $\mathrm{As}(\mathrm{V})$. Samples c and d signified the $\delta \mathrm{MnO}_{2}$ when As(III) was predissolved in the reaction solution. Additionally, no $\mathrm{Ca}^{2+}$ was added in experimental systems of samples a and $\mathrm{c}$, and $1 \mathrm{mM} \mathrm{Ca}^{2+}$ was present for samples b and $\mathrm{d}$. In the FTIR spectra, the peaks at $1639 \mathrm{~cm}^{-1}$ were ascribed to the deformation of water molecules, while the peaks between 1390 and $1432 \mathrm{~cm}^{-1}$ were attributed to the vibration of $\mathrm{NO}_{3}^{-}$, which was used for ionic strength adjustment. The peaks at 1053 and $1093 \mathrm{~cm}^{-1}$ could be assigned to the vibration of $\equiv \mathrm{Mn}-\mathrm{OH}$, which was weakened in the presence of $\mathrm{Ca}^{2+}$ (Figs. 5b and 5d). Sample b showed a more obvious decrease in the $\equiv \mathrm{Mn}-\mathrm{OH}$ peak (e.g., $1053 \mathrm{~cm}^{-1}$ ) than sample $d$, probably due to a higher degree of complexation between
$\mathrm{Ca}^{2+}$ and $\equiv \mathrm{Mn}-\mathrm{OH}$. Our SEM/EDX analysis substantiated that sample b had a higher Ca content (1.98\%) than sample $d(0.37 \%)$.

The $885 \mathrm{~cm}^{-1}$ peak was assigned to the As-O collision within the adsorbed As species, rather than to the As-O surface complex. Goldberg and Johnston reported that the As-O bands in the $0.1 \mathrm{M}$ $\mathrm{As}(\mathrm{V})$ solution at $\mathrm{pH} 5$ appeared at 878 and $907 \mathrm{~cm}^{-1}$ due to the As-O collision of $\mathrm{AsO}_{2}(\mathrm{OH})_{2}^{-}$[19]. However, after $\mathrm{As}(\mathrm{V})$ adsorption onto amorphous iron oxides, two new bands at 824 and $861 \mathrm{~cm}^{-1}$ were observed, which were respectively assigned to the $\mathrm{Fe}-\mathrm{O}-$ As complex and the adsorbed arsenic species in uncomplexed As species [19]. In this work, the slight shift of the As-O band indicated that the formation of surface complexes (e.g., Ca-O-As, $\mathrm{Mn}-\mathrm{O}-\mathrm{As}$ ) was negligible. Therefore, the bridging effect of $\mathrm{Ca}^{2+}$ was weak in arsenic adsorption by $\delta \mathrm{MnO}_{2}$.

It should be noted that the $\mathrm{As}(\mathrm{V})$ absorption peak at $885 \mathrm{~cm}^{-1}$ also appeared in sample $c$ and sample d (Fig. 5) even when only As(III) was present in the reaction solution, implying the interfacial oxidation of $\mathrm{As}(\mathrm{III})$ to $\mathrm{As}(\mathrm{V})$ during $\mathrm{As}(\mathrm{III})$ adsorption onto $\delta \mathrm{MnO}_{2}$.

\subsubsection{Mechanism of enhanced pollutant adsorption onto $\delta \mathrm{MnO}_{2}$ by $\mathrm{Ca}^{2+}$ ions}

As mentioned above, $\mathrm{Ca}^{2+}$ could enhance pollutant removal by increasing the surface potential of $\delta \mathrm{MnO}_{2}$ and reducing the repulsive force, as well as promoting $\delta \mathrm{MnO}_{2}$ aggregation to increase the filtration efficiency of $\delta \mathrm{MnO}_{2}$ particles. In addition, if the model pollutants could form complexes with $\mathrm{Ca}^{2+}$ and the solution $\mathrm{pH}$ was higher than the $\mathrm{pH}_{\mathrm{PZC}}$ of $\delta \mathrm{MnO}_{2}$, the bridging effect of $\mathrm{Ca}^{2+}$,

$\mathrm{P}^{-}+\mathrm{Ca}^{2+}=[\mathrm{Ca}-\mathrm{P}]^{+}$,

$\equiv \mathrm{MnOHOH}^{-}+[\mathrm{Ca}-\mathrm{P}]^{+}=\equiv \mathrm{MnO}-\mathrm{Ca}-\mathrm{P}+\mathrm{H}_{2} \mathrm{O}$,

where $\mathrm{P}^{-}$represents the deprotonated model pollutant, would also boost pollutant removal.

Based on the experimental results discussed above, the mechanisms of $\mathrm{Ca}^{2+}$ facilitating the adsorption of different pollutants onto $\delta \mathrm{MnO}_{2}$ are proposed in Fig. 6 .

\section{Summary}

$\mathrm{Ca}^{2+}$ could significantly impact the surface characteristics of $\delta \mathrm{MnO}_{2}$ through its complexation with $\mathrm{Mn}-\mathrm{OH}$. The presence of

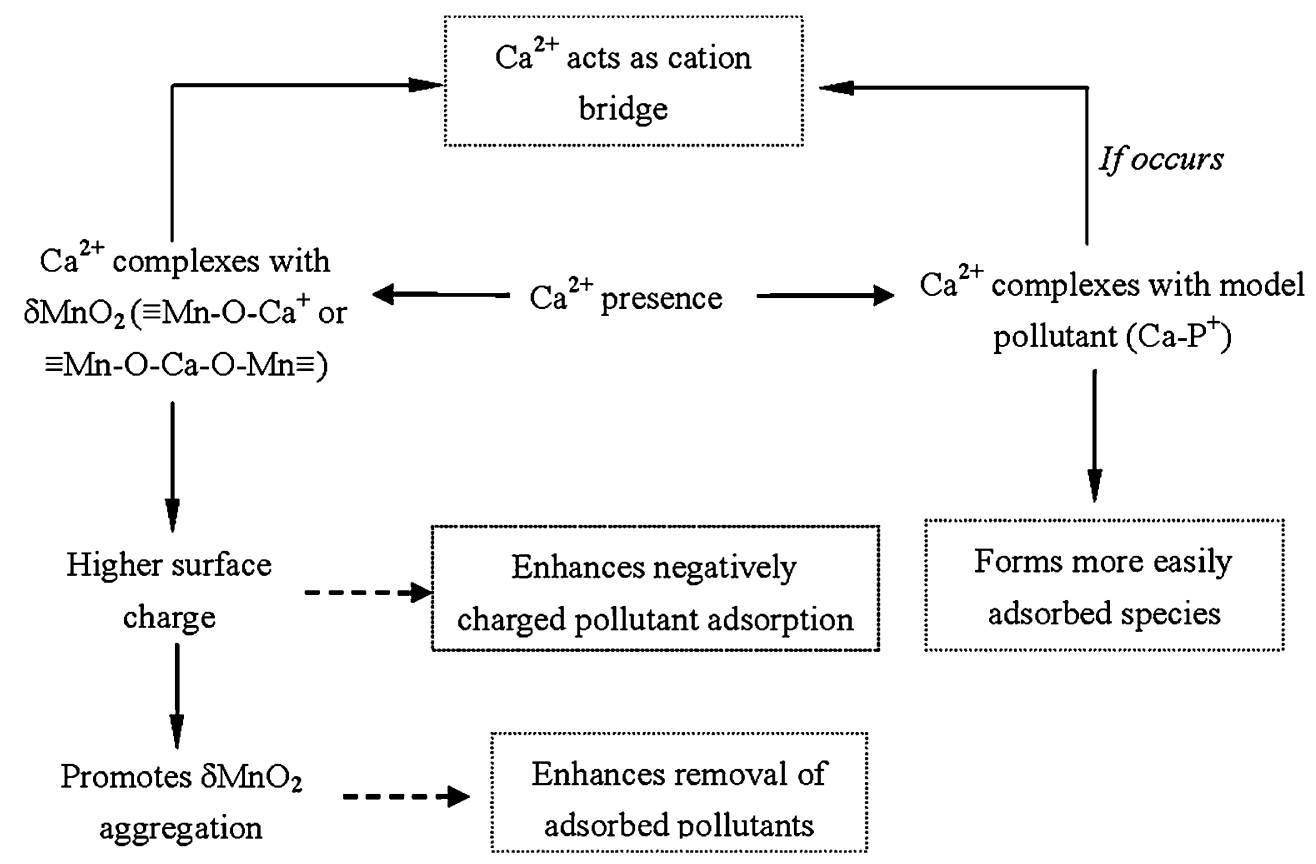

Fig. 6. Proposed mechanisms for $\mathrm{Ca}^{2+}$ facilitation of pollutant adsorption onto $\delta \mathrm{MnO}_{2}$. 
$\mathrm{Ca}^{2+}$ increased the $\zeta$ potential of $\delta \mathrm{MnO}_{2}$ and promoted $\delta \mathrm{MnO}_{2}$ aggregation, which was beneficial for the removal of negatively charged pollutants. However, the positive effect of $\mathrm{Ca}^{2+}$ on pollutant adsorption onto $\delta \mathrm{MnO}_{2}$ was pollutant-dependent. In general, $\mathrm{Ca}^{2+}$ would exert a more positive effect on pollutants that can complex with $\mathrm{Ca}^{2+}$ (e.g., HA) than on pollutants that cannot complex with $\mathrm{Ca}^{2+}$ (e.g., arsenic species). The bridging effect of $\mathrm{Ca}^{2+}$ dominated its effect on pollutant adsorption onto $\delta \mathrm{MnO}_{2}$.

\section{Acknowledgments}

This work was supported by the National Natural Science Foundation of China (Grant 50608067) and the Funds for Creative Research Groups of China (Grant 50621804).

\section{References}

[1] B.A. Manning, S.E. Fendorf, B. Bostick, D.L. Suarez, Environ. Sci. Technol. 36 (2002) 976.

[2] N.D. McCafferty, M.E. Callow, L. Hoggett, B. Holden, B.S.C. Leadbeater, Water Res. 34 (2000) 2199.

[3] A. Genz, A. Kornmuller, M. Jekel, Water Res. 38 (2004) 3523.

[4] R.X. Liu, H.X. Tang, Water Res. 34 (2000) 4029.
[5] S. Kaneco, K. Itoh, H. Katsumata, T. Suzuki, K. Masuyama, K. Funasaka, K. Hatano, K. Ohta, Environ. Sci. Technol. 37 (2003) 1448.

[6] R.P. Liu, X. Li, S.J. Xia, Y.L. Yang, R.C. Wu, G.B. Li, Water Environ. Res. 79 (2007) 2260.

[7] R.P. Liu, Y.L. Yang, G.B. Li, W.J. He, H.D. Han, Front. Environ. Sci. Eng. China 1 (2007) 240.

[8] R.P. Liu, B.L. Yuan, X. Li, S.J. Xia, Y.L. Yang, G.B. Li, High Technol. Lett. 12 (2006) 30.

[9] J. Gregory, D.W. Nelson, in: Solid-Liquid Separation, Ellis Horwood, Chichester, 1984.

[10] K. Nakamoto, Infrared and Raman Spectra of Inorganic and Coordination Compound, third ed., Wiley, New York, 1978.

[11] J.A. Davis, D.B. Kent, in: M.F. Hochella Jr., A.F. White (Eds.), Mineral-Water Interface Geochemistry, Mineralogical Society of America, in: Rev. Mineral., vol. 23, Wiley, New York, 1990, p. 177.

[12] K. Anazawa, H. Ohmori, Chemosphere 45 (2001) 807.

[13] B. Gu, J. Schmitt, Z. Chen, L. Liang, J.F. McCarthy, Environ. Sci. Technol. 28 (1994) 38.

[14] W. Yao, F.J. Millero, Environ. Sci. Technol. 30 (1996) 536.

[15] C.P. Schulthess, C.P. Huang, Soil Sci. Soc. Am. J. 55 (1991) 34.

[16] R.P. Liu, B.L. Yuan, X. Li, S.J. Xia, Y.L. Yang, G.B. Li, High Technol. Lett. 12 (2006) 30.

[17] P.M. Swash, A.J. Monhemius, in: Conference on Mining and the Environment Sudbury, Ontario, 1995, 28 May-1 June, pp. 17-28.

[18] L.P. Qiu, H.R. Liu, Chin. Water Wastewater 16 (2000) 58.

[19] S. Goldberg, C.T. Johnston, J. Colloid Interface Sci. 234 (2001) 204. 